\title{
Risk Factors Associated with Carotid Artery Puncture following Landmark-Guided Internal Jugular Vein Cannulation Attempts
}

\author{
Radmilo J. Jankovic ${ }^{a}$ Marija S. Pavlovic ${ }^{a}$ Miodrag M. Stojanovic ${ }^{b}$ \\ Biljana S. Stosic ${ }^{a}$ Dragan J. Milic ${ }^{c}$ Nebojsa S. Ignjatovic ${ }^{c}$ Angelina N. Bogicevic $^{a}$ \\ Dragana R. Djordjevic ${ }^{a}$ Nenad N. Savic ${ }^{a}$ \\ ${ }^{a}$ Department of Anesthesiology and Intensive Care, School of Medicine, University of Nis, ${ }^{b}$ Department of \\ Medical Statistics, Institute for Public Health, School of Medicine, University of Nis, and ${ }^{~}$ Clinic for General \\ Surgery, Clinical Center Nis, Nis, Serbia
}

\section{Key Words}

Central venous cannulation · Complications · Anesthesia $\cdot$

Operating room

\begin{abstract}
Objective: The relationship between certain risk factors and carotid artery puncture (CAP) as an early mechanical complication following internal jugular vein cannulation attempts (IJVCAs) was evaluated. Methods: In a retrospective 1-year observational single-center study, 86 IJVCAs conducted in the operating room by 4 competent anesthesiologists were evaluated. Age, gender, puncture side, number of cannulation attempts, circumstances of the procedure and incidence of CAP were obtained from medical records. Results: Of the 86 IJVCAs performed in patients aged 18-75 years, CAP occurred in $8(9.3 \%): 5(5.8 \%)$ in patients $>65$ years and $3(3.5 \%)$ in patients $<65$ years of age. CAP was not associated with patient's age $(p=0.11)$ and gender $(p=0.76)$. Multiple cannulation attempts $(\mathrm{OR}=26.25 ; 95 \% \mathrm{Cl}=4.52-152.51 ; \mathrm{p}<$ 0.001 ) and placement of CVC under emergency conditions $(\mathrm{OR}=14.84 ; 95 \% \mathrm{Cl}=1.73-127.22 ; \mathrm{p}=0.014)$ increased the risk for CAP significantly. Also, the risk for CAP was higher when IJVCAs were performed before induction of general
\end{abstract}

\section{KARGER}

Fax +4161306 1234

E-Mail karger@karger.ch

www.karger.com
(C) 2011 S. Karger AG, Basel

1011-7571/11/0206-0562\$38.00/0

Accessible online at:

www.karger.com/mpp anesthesia (OR $=15.75 ; 95 \% \mathrm{Cl}=1.83-135.1 ; \mathrm{p}=0.019)$. CAP was more likely to happen during left-sided than right-sided IJVCA (OR $=5.98 ; 95 \% \mathrm{Cl}=1.29-27.59 ; \mathrm{p}=0.022)$. In addition, left-sided attempts considerably increased the risk for multiple cannulation attempts $(\mathrm{OR}=2.782 ; 95 \% \mathrm{Cl}=1.342-3.965$; $\mathrm{p}<0.01)$. Also, manifold cannulation attempts were more frequent if the IJVCA was performed before induction of anesthesia ( $O R=4.219 ; \mathrm{Cl}=1.579-11.271 ; \mathrm{p}=0.004)$. Conclusions: Our results strongly suggest that left-sided, multiple IJVCAs, performed under emergency conditions in conscious patients in the operating room, represent considerable risks for possible CAP.

Copyright $\odot 2011$ S. Karger AG, Basel

\section{Introduction}

Central venous catheters (CVCs) are indwelling devices for daily clinical practice for treatment of several diseases [1]. Despite their utility, placement of CVCs is associated with potentially severe complications, which at times can be fatal. Severe vascular complications are not always easy to recognize. Generally, they are divided into mechanical, infectious and thromboembolic com- 
plications. Mechanical complications are important because they are usually immediate and associated with a significant mortality rate. In addition, these complications may increase the length and costs of hospital stay as well as the need for subsequent interventions [2]. However, ultrasound-guided technique has been shown to be useful in obtaining successful catheterization with a reduced complication rate [3-5]. Because of these studies, nearly 10 years ago, the US Agency for Healthcare Research and Quality Evidence Report recommended that all central cannula placements should be guided by realtime ultrasound. Unfortunately, these recommendations are not widely followed in practice.

CVC placement in the internal jugular vein (IJV) is the most frequently used approach. The insertion procedure is relatively simple: the route by which the guide wire is advanced is comparatively straight and catheterization of the jugular vein has relatively few early complications. Hence, CVC insertion into the IJV has comparative advantages to placement attempts at other puncture sites when rapid insertion is required. The most common mechanical complication associated with internal jugular vein cannulation attempts (IJVCA) is carotid artery puncture (CAP), due to its close proximity to the IJV [6] as evidenced by the report of Ruesch et al. [7], in which arterial puncture occurred significantly more frequently with the jugular approach compared to the subclavian approach (3.0 vs. $0.5 \%$, RR 4.70, 95\% CI $=2.05-10.77$ ).

Several studies have identified factors associated with CAP following CVC placement, including low or high body mass index, prior catheterization, prior surgery, prior radiotherapy, advanced age and the time needed for catheter placement $[8,9]$. In this retrospective observational study we analyzed CAP as an early complication associated with IJVCA and sought to elucidate the relationship between certain risk factors and the complication rate.

\section{Subjects and Methods}

This study was conducted at the Clinic for General Surgery of the University Hospital of the Medical School of Nis, an urban teaching hospital where approximately 5,000 operations are performed per year, including abdominal, thoracic, vascular and colorectal surgeries. Generally, more than 4,000 of these procedures are elective, whereas the remaining 1,000 are emergency operations. The study was approved by our Medical Center Institutional Review Board.

Our medical records consisted of 86 IJVCA procedures performed exclusively in the operating room over a 1-year period. Patients included in this study were 18-75 years old, both male and female. The CVCs were placed by experienced anesthesiologists defined as having previously placed at least 60 IJVCs independently.

All catheters were inserted using the Seldinger technique. Based on the physician's preference, the IJV was cannulated either by the anterior or posterior approach. After anatomical landmarks were visualized, the skin was prepared with chlorhexidine and draped. The catheters were introduced during exhalation to minimize the possibility of air embolization and artificial pneumothorax. Triple-lumen central vein catheters of 7-8 $\mathrm{Fr}$ and $30 \mathrm{~cm}$ in length (Certofix ${ }^{\circledR}, B$. Braun Melsungen AG, Germany) were used. Catheter position was confirmed preliminarily by free venous blood return, free flow of fluid through all ports and pressure conduction. A monitoring set (Combitrans ${ }^{\circledR}$, B. Braun Melsungen AG) was used for measuring central venous pressure. Maximum central venous pressure was regarded as $25 \mathrm{~mm} \mathrm{Hg}$ and pressure above $25 \mathrm{~mm} \mathrm{Hg}$ was considered a possible sign that the needle was in the artery. This fact was confirmed by disconnecting the syringe from the needle, followed by pulsatory back flow. After insertion, the CVC was sutured into place and covered with a sterile dressing. All patients routinely had a chest radiograph for definite confirmation of the position of the CVC. Ultrasound was not used in any of the procedures.

A cannulation attempt was defined by the number of skin punctures, and the number of percutaneous attempts was recorded. IJVCAs were defined either as an emergency procedure if the anesthesiologist concluded that any delay would be harmful to the patient. The time relationship between induction of anesthesia and cannulation attempt was defined as the time before and after induction of anesthesia.

Age, gender, procedural characteristics, and incidence of carotid artery puncture were obtained from medical records. By our institution's protocol, all items associated with anesthesia including conditions of central venous cannulation attempts and the occurrence of related complications were required to be recorded and well documented in the aforementioned form. Patients were divided into two groups according to age, those under and over 65 years of age. Procedure characteristics were puncture side, number of percutaneous attempts and circumstances of the procedure (defined as elective or as an emergency, and the time before or after induction of anesthesia). The database was analyzed by a statistician who is a co-author.

Statistical evaluation was performed using SPSS 10.0 for Windows (SPSS Inc., Chicago, Ill., USA). A p value of 0.05 from Fisher's exact test was considered to be a statistically significant difference. Logistic regression analysis was applied for prediction of complications by the procedure's characteristics and the influence of gender and age on the complication rate. Associations were described by odds ratios (OR).

\section{Results}

Patient characteristics are presented in table 1 . There were 64 right-sided IJVCAs and 22 left-sided IJVCAs. Thirty-two (37\%) of all catheters were placed during emergency procedures. Of all IJVCAs, 72 (over 83\%) were successful after a single attempt, and $14(16 \%)$ required 
two or more attempts for successful placement. Overall CAP rate was 8 (9.3\%). CAP was not significantly associated with patient's age $(\mathrm{p}=0.11)$ and gender $(\mathrm{p}=0.76)$, but among patients with complications, 5 (62.5\%) were older than 65 years.

Considering the patients in whom CAP occurred, we discovered that the site of the puncture significantly affected the complication rate. In fact, the complication rate was higher among patients with left-sided IJVCA $(\mathrm{n}=5$, $62.5 \%$ ) compared to right-sided IJVCA ( $\mathrm{n}=3,37.5 \%, \mathrm{p}=$ 0.022). Placement of CVC under emergency conditions also led to a greater number of complications ( $\mathrm{n}=7$, $87.5 \%)$ than elective procedures $(\mathrm{n}=1,12.5 \%, \mathrm{p}=0.014)$. Patients who were not under anesthesia had a higher complication rate as well $(\mathrm{n}=7,87.5 \%, \mathrm{p}=0.012)$. The number of attempts was significantly associated with the complication rate. IJVCAs requiring a single puncture had a complication rate of $25 \%$, whereas two or more attempts had a complication rate of $75.0 \%$ in patients with CAP (table 2).

Univariate logistic regression analysis showed that multiple attempts were the strongest risk factor for complications (table 3). Also, multiple cannulation attempts were more frequent if the IJVCA was performed before induction of anesthesia $(\mathrm{OR}=4.219$; $\mathrm{CI}=1.579-11.271$; $\mathrm{p}=0.004)$. CAP was more likely to happen during leftsided IJVCA. Moreover, left-sided attempts increased the risk for multiple percutaneous attempts $(\mathrm{OR}=2.782 ; 95 \%$ $\mathrm{CI}=1.342-3.965 ; \mathrm{p}<0.01)$. Placement of CVC under emergency conditions increased the risk of complications several times. There was no need for surgery to be postponed as a result of CAP since there were no clinically important adverse events associated with CAP.

\section{Discussion}

Our overall puncture rate of the internal carotid artery of $9.3 \%$ is within the range of previous studies of $5-19 \%$ [9-11]. In the study by Schummer et al. [11] of the mechanical complications of central venous cannulation, arterial punctures occurred more often in the IJV approach than in the subclavian approach. In the study by Sulek et al. [12], the carotid artery was punctured in 10 of $60(17 \%)$ patients, who were undergoing elective abdominal, vascular, or cardiothoracic surgery under anesthesia and mechanical ventilation.

Four factors were found to correlate with the complication rate: placement of CVC under emergency conditions, cannulation attempt before or after induction of
Table 1. Patient characteristics and complication rate

\begin{tabular}{lllll}
\hline Characteristics & $\begin{array}{l}\text { IJVCA } \\
(\mathrm{n}=86)\end{array}$ & $\begin{array}{l}\text { CAP } \\
(\mathrm{n}=8)\end{array}$ & $\begin{array}{l}\text { Fisher's } \\
\mathrm{p}\end{array}$ \\
\hline \multirow{2}{*}{ Age } & $\begin{array}{l}>65 \text { years } \\
<65 \text { years }\end{array}$ & $\begin{array}{l}29(33.7) \\
57(66.3)\end{array}$ & $\begin{array}{l}5(62.5) \\
3(37.5)\end{array}$ & 0.11 \\
\hline \multirow{2}{*}{ Gender } & $\begin{array}{l}\text { male } \\
\text { female }\end{array}$ & $42(49)$ & $3(37.5)$ & 0.76 \\
& $44(51)$ & $5(62.5)$ & \\
\hline
\end{tabular}

Numbers with percentages in parentheses. Age $=53 \pm 6$ years (mean $\pm \mathrm{SD}$ ).

Table 2. Characteristics and complication rate of procedure

\begin{tabular}{lllll}
\hline Characteristics & $\begin{array}{l}\text { IJVCA } \\
(\mathrm{n}=86)\end{array}$ & $\begin{array}{l}\text { CAP } \\
(\mathrm{n}=8)\end{array}$ & $\begin{array}{l}\text { Fisher's } \\
\mathrm{p}\end{array}$ \\
\hline $\begin{array}{llll}\text { Puncture } \\
\text { side }\end{array}$ & $\begin{array}{l}\text { right } \\
\text { left }\end{array}$ & $\begin{array}{l}64(74.4) \\
22(25.6)\end{array}$ & $\begin{array}{l}3(37.5) \\
5(62.5)\end{array}$ & 0.02 \\
\hline $\begin{array}{l}\text { Number } \\
\text { of attempts }\end{array}$ & single & $72(83.7)$ & $2(25.0)$ & 0.0001 \\
\hline $\begin{array}{l}\text { Circum- } \\
\text { stances of }\end{array}$ & elective & $14(16.3)$ & $6(75.0)$ & \\
procedure & emergency & $32(62.8)$ & $1(12.5)$ & 0.004 \\
& BIA & $38(44.2)$ & $7(87.5)$ & \\
\hline
\end{tabular}

Numbers with percentages in parentheses. BIA $=$ Before induction of anesthesia; AIA = after induction of anesthesia.

general anesthesia, number of percutaneous punctures per attempt and left-sided IJV approach. A probable explanation for complications associated with the placement of CVC under emergency conditions is due to stress. However, other studies $[13,14]$ reported a complication rate that was even lower in emergency situations because the most experienced operator immediately available assumes responsibility. Although the use of ultrasound can facilitate cannulation of the IJV performed in Emergency Departments, acute adverse events have been reported in approximately one fifth of ultrasound-guided internal jugular central line attempts with an accidental CAP rate of $2 \%$ [15]. CVC placement under emergency conditions, attempted in $87.5 \%$ of the patients in whom complications occurred, represents a statistically significant risk compared to CVC attempts during elective procedures.

The number of cannulation attempts before or after induction of general anesthesia affected the complication 
rate. When IJVCA was performed while preparing for surgery on a conscious patient the risk of CAP increased 15 times compared to patients who were under anesthesia, most probably because conscious patients are able to move during the procedure. Alert patients sometimes did not cooperate, which then led to multiple attempts. Patients who are under anesthesia are completely relaxed and unable to move. It is obvious why the number of percutaneous punctures per attempt was 4 times higher in the group of patients who were not under anesthesia.

The number of percutaneous punctures per attempt was also significantly associated with the complication rate, similar to findings in other studies $[8,10]$ in which the complication rate was $4.3 \%$ for one puncture, $10.9 \%$ for two percutaneous punctures, and $24.0 \%$ for three or more attempts [8]. These results were found in a prospective randomized trial of ultrasound-guided location of the subclavian vein compared to a standard CVC insertion procedure [8]. Ultrasound was also shown to significantly reduce the total number of punctures per attempt when emergency central access was required [16]. Schummer et al. [11] pointed out that the risk of mechanical complications increased nearly 10 times with two attempts, and that the majority of mechanical complications occurred in procedures involving more than two attempts. This was also confirmed by our data in which attempts requiring two or more percutaneous punctures had a $75 \%$ rate of CAP. Hence, some authors discouraged more than two percutaneous punctures by the same anesthesiologist at the same place [8].

The higher complication rate associated with our leftsided IJV approach is in agreement with the data available in the literature, where the right-sided approach is preferable because the right IJV is shorter and straighter than the left. Furthermore, a recent study [17] concerning the use of axial computed tomography slices found that both vertical and horizontal diameters of the right IJV were significantly larger than those of the left IJV $(1.51 \pm 0.41$ vs. $1.13 \pm 0.34 \mathrm{~cm})$. In the same study, the right IJV was also found to run more superficially than the left IJV. Here, the high rate $(62.5 \%)$ of complications in patients for whom CVC placement was attempted on the left side could be attributed to the fact that most of our operators were right-handed. A right-handed operator may have greater difficulty inserting a left-sided line. These findings are in accordance with the study by Sulek et al. [12], who reported that cannulation of the left IJV was more time-consuming, required more attempts, and was associated with a greater number of complications compared to the right side.

Carotid Puncture after Central Vein Cannulation
Table 3. Logistic regression analysis for complications and their determinants

\begin{tabular}{|c|c|c|c|c|}
\hline & \multicolumn{2}{|l|}{ CAP } & \multirow[t]{2}{*}{ OR } & \multirow[t]{2}{*}{$95 \% \mathrm{CI}$} \\
\hline & yes $(n=8)$ & no $(\mathrm{n}=78)$ & & \\
\hline \multicolumn{5}{|l|}{ Age } \\
\hline$<65$ years & $3(37.5)$ & $54(69.2)$ & 1 & \\
\hline$>65$ years & $5(62.5)$ & $24(30.8)$ & 3.75 & $0.83-16.96$ \\
\hline \multicolumn{5}{|l|}{ Gender } \\
\hline Male & $3(37.5)$ & $39(50.0)$ & 1 & \\
\hline Female & $5(62.5)$ & $39(50.0)$ & 1.67 & $0.37-7.46$ \\
\hline \multicolumn{5}{|l|}{ Puncture side } \\
\hline Right & $3(37.5)$ & $61(78.2)$ & 1 & \\
\hline Left & $5(62.5)$ & $17(21.8)$ & 5.98 & $1.29-27.59$ \\
\hline \multicolumn{5}{|c|}{ Number of attempts } \\
\hline Single & $2(25.0)$ & $70(89.7)$ & 1 & \\
\hline$\geq 2$ & $6(75.0)$ & $8(10.3)$ & 26.25 & $4.5-152.51$ \\
\hline \multicolumn{5}{|c|}{ Circumstances of procedure } \\
\hline Elective & $1(12.5)$ & $53(67.9)$ & 1 & \\
\hline Emergency & $7(87.5)$ & $25(32.1)$ & 14.84 & $1.73-127.2$ \\
\hline AIA & $1(12.5)$ & $47(63.96)$ & 1 & \\
\hline BIA & $7(87.5)$ & $31(36.04)$ & 15.750 & $1.83-135.1$ \\
\hline
\end{tabular}

Numbers with percentages in parentheses. AIA = After induction of anesthesia; BIA = before induction of anesthesia.

Patient characteristics were not associated with CAP, but among patients with CAP, $62.5 \%$ were more than 65 years old. Variant anatomy of the IJV has been documented for elderly, uremic, cancer and pediatric patients [18]. The elderly have a greater overlap of the IJV and carotid artery due to the carotid artery becoming tortuous and elongated with increasing age. The most common variation is the IJV overlying the carotid artery [19]. In an ultrasound study involving 1,009 patients, Trionans et al. [19] demonstrated that age over 60 years is a predictive factor for IJV variation. Eisen et al. [20], however, failed to establish a correlation between a patient's age and the complication rate. This study involved 385 consecutive femoral, subclavian and internal jugular CVC attempts.

\section{Conclusion}

Considering the placement of CVC in operating rooms, our results strongly suggest that left-sided and multiple IJVCAs, performed under emergency conditions in conscious patients, should be considered risk factors for possible carotid artery puncture.

Med Princ Pract 2011;20:562-566 


\section{References}

-1 Paoletti F, Ripani U, Antonelli M, Nicoletta G: Central venous catheters: observations on the implantation technique and its complications. Minerva Anesthesiol 2005;71:555560.

$>2$ McGee DC, Gould MK: Preventing complications of central venous catheterization. $\mathrm{N}$ Engl J Med 2003;348:1123-1133.

3 Miller AH, Roth BA, Mills TJ, Woody JR, Longmoor CE, Foster B: Ultrasound guidance versus the landmark technique for the placement of central venous catheters in the emergency department. Acad Emerg Med 2002;9:800-805.

4 Hayashi H, Amano M: Does ultrasound imaging before puncture facilitate internal jugular vein cannulation? Prospective randomized comparison with landmark-guided puncture in ventilated patients. J Cardiothorac Vasc Anesth 2002;16:572-575.

5 Karakitsos D, Labropoulos N, De Groot E, Patrianakos AP, Kouraklis G, Poularas J, Samonis G, Tsoutsos DA, Konstadoulakis MM, Karabinis A: Real-time ultrasound-guided catheterisation of the internal jugular vein: a prospective comparison with the landmark technique in critical care patients. Crit Care 2006;10:R162.

-6 Denys BG, Uretsky BF: Anatomical variation of internal jugular vein location: impact on central venous access. Crit Care Med 1991; 19:1516-1519. $\checkmark 7$ Ruesch S, Walder B, Tramèr MR: Complications of central venous catheters: internal jugular versus subclavian access: a systematic review. Crit Care Med 2002;30:454-460.

$>8$ Mansfield PF, Hohn DC, Fornage BD, Gregurich MA, Ota DM: Complications and failures of subclavian-vein catheterization. N Engl J Med 1994;331:1735-1738.

$\checkmark 9$ Baley PL, Whitaker EE, Palmer LS, Glance LG: The accuracy of the central landmark used for central venous catheterization of the internal jugular vein. Anesth Analg 2006; 102:1327-1332.

- 10 Lefrant JY, Muller L, De la Coussaye JE, Prudhomme M, Ripart J, Gouzes C, Peray P, Saissi G, Eledjam JJ: Risk factors and immediate complication of subclavian vein in critically ill patients. Intensive Care Med 2002; 28:1036-1041.

-11 Schummer W, Schummer C, Rose N, Niesen WD, Sakka SG: Mechanical complications and malpositions of central venous cannulations by experienced operators: a prospective study of 1794 catheterizations in critically ill patients. Intensive Care Med 2007;33:10551059.

12 Sulek CA, Blas ML, Lobato EB: A randomized study of left versus right internal jugular vein cannulation in adults. J Clin Anesth 2000;12:142-145.

13 Steele R, Irvin C: Central line mechanical complication rate in emergency medicine patients. Acad Emerg Med 2001;8:204-207.
14 Puri VK, Carlson RW, Bander JJ: Complication of vascular catheterization in critically ill: a prospective study. Crit Care Med 1980; 8:495-499.

15 Theodoro D, Krauss M, Kollef M, Evanoff B: Risk factors for acute adverse events during ultrasound-guided central venous cannulation in the emergency department. Acad Emerg Med 2010;17:1055-1061.

16 Balls A, LoVecchio F, Kroeger A, Stapczynski JS, Mulrow M, Drachman D; Central Line Emergency Access Registry Investigators: Ultrasound guidance for central venous catheter placement: results from the Central Line Emergency Access Registry Database. Am J Emerg Med 2010;28:561-567.

17 Ishizuka M, Nagata H, Takagi K, Kubota K: Right internal jugular vein is recommended for central venous catheterization. J Invest Surg 2010;23:110-114.

18 Malcom GE 3rd, Raio CC, Poordabbagh AP, Chiricolo CC: Difficult central line placement due to variant internal jugular vein anatomy. J Emerg Med 2008;35:189-191.

19 Trionans CA, Kuwik RJ, Pasqual JR, Lim AJ, Odasso DP: Internal jugular vein and carotid artery anatomic relation as determined by ultrasonography. Anesthesiology 1996;85: 43-48.

20 Eisen LA, Narasimhan M, Berger JS, Mayo $\mathrm{PH}$, Rosen MR, Schneider RF: Mechanical complications of central venous catheters. J Intensive Care Med 2006;21:40-46. 